\title{
China's New Silk Road: Policies and Implications*
}

\author{
Jun Yeop Lee**, Kisoon Hyun ${ }^{* * *}$, Ling Jin ${ }^{* * * *}$
}

\begin{abstract}
Using the Social Network Analysis(SNA) method, this paper examines inter-country relationships between countries that may be part of the New Silk Road. Based on bilateral-trade data from more than 70 countries, the paper provides a more vivid understanding of overall features and effects of the New Silk Road policy. According to the results, India, Turkey, and Russia have the highest degree centrality, indicating that the success of the New Silk Road policy depends mainly on the ability of the Chinese government to incorporate these countries. Among European countries, only Germany can be successfully incorporated into the New Silk Road network. In addition, Central Asian countries such as Kazakhstan and Uzbekistan show no potential as hubs in the network. Most importantly, China has a dominant position in the New Silk Road network. China's focal and dominating status is also supported by the fact that there is no change in the clustering coefficient in the network, which implies that the Chinese government has to absorb into the system those countries that are less likely to benefit from the policy.
\end{abstract}

Key Word: China's New Silk Road, Social Network Analysis, Degree Centrality

JEL classification: $O 19$, O20, F14, O50

\footnotetext{
* This work was supported by Inha University as well as by the Ministry of Education of the Republic of Korea and the National Research Foundation of Korea(NRF-2015S1A5B5A02015389).

** Corresponding Author: Professor, Department of International Trade and Regional Studies, Inha University, 100 Inha-ro, Incheon, Korea (E-mail: jylee@inha.ac.kr).

*** Research Professor, Korean Geographic Research Institute, Sungshin University, 2 Bomun-ro 34da-gil, Seongbuk-gu, Seoul, Korea (E-mail: kshyun147@gmail.com).

**** Doctoral Candidate, Department of Economics, Inha University, 100 Inha-ro, Incheon, Korea (E-mail: candyjin315@naver.com).
} 


\section{Introduction}

What are the economic implications of the New Silk Road project? Can the dynamic features of interconnections between countries that may be induced by the New Silk Road be predicted? Is there any analytic methodology that can assess the effects and repercussions of the New Silk Road policy? In addition, through some analytic methodology, can the country playing a core role in the implementation of the New Silk Road be predicted? This paper focuses on addressing these important questions.

The New Silk Road project was initiated in 2013 by Xi Jinping, the president of China and the general secretary of the Chinese Communist Party. The project was followed by the notion "Chinese Dream, Great Revival of the Chinese Nation," which was underscored in President Xi's inaugural speech in 2012. The project was announced by President Xi, and there is little doubt that the New Silk Road is a product of the highest priority and will be implemented as a long-term goal of the Chinese government.

The New Silk Road project is composed of five routes, three of which are land routes from China to Western Europe through Central Asia, the Middle East, and Russia. The remaining two are sea routes through the South China Sea, the Indian Ocean, and the Mediterranean Sea. The routes include more than 60 countries with distinct political, economic, cultural, and geographic conditions. These countries range from less economic developed ones to more developed ones and from extremely religiously ones to highly liberal ones, and for these reasons, China is likely to face serious challenges in paving new trade and transportation routes.

From a route-oriented perspective, the New Silk Road project can be simplified into the construction of an efficient trade and logistics network across Eurasia. From this perspective, the New Silk Road can be interpreted as the formation of an efficient network across spatially distributed countries. Countries are defined as nodes, and the volume of trade between countries can be identified as direct links. In this sense, the social network analysis (SNA) method, which focuses on uncovering patterns of relationships between interacting units, can be an appropriate research methodology. Using the SNA method, this paper analyzes the dynamic features of the New Silk Road project.

Using inter-country trade data and focusing on an inter-country social network, this paper examines the comparative status of each country and determines the network-oriented implications of the New Silk Road. The rest of this paper is organized as follows: Section 2 summarizes the New Silk Road project based on policy goals of the Chinese government and details its five routes. Section 3 describes the concept of centrality and descriptive features of the New Silk Road network. In addition, the section introduces the group 
structure of the New Silk Road. Section 4 analyzes the role of each country based on the whole network including China. Section 5 discusses the policy implications of the New Silk Road network from the perspective of China as well as from that of other represented countries.

\section{A General Overview of the New Silk Road}

The New Silk Road was officially announced in 2013 by President Xi. The land-based silk road was announced during his visit to Kazakhstan in September 2013, and the maritime silk road, during his visit to Indonesia in October 2013. The New Silk Road is also referred to as the "One Belt One Road" (YidaiYilu), which means a broad economic region covering a land-based silk road and a maritime silk road. It has been reported that the New Silk Road policy would remain in effect until 2049, the centennial anniversary of the Chinese Communist Party (CPC). Therefore, the New Silk Road policy is a 30-year plan comparable to post-1978 economic reform policies, which have fundamentally changed the Chinese economy.

Routes of the New Silk Road: The core goal of the New Silk Road is to develop and reinforce connections between China and Europe. There are currently five routes of the New Silk Road.

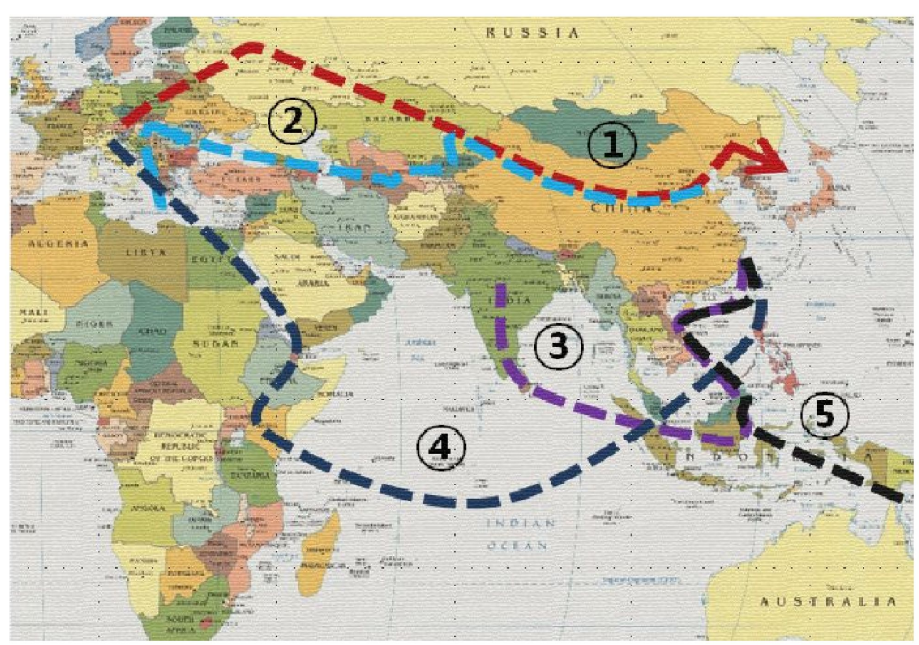

Figure 1.

Five routes of the New Silk Road 
The Northern Line passes through China, Kazakhstan, Russia, Belarus, and Central Europe (Line 1 in Figure 1). The Central Line starts at Zhengzhou and Xian, China, and goes through Kazakhstan, Kyrgyzstan, Uzbekistan, Turkmenistan, Azerbaijan, Georgia, the Black Sea, Romania, and Hungary (Line 2 in Figure 1). The Southern Line moves through Guangzhou, China, to Vietnam, Malaysia, Indonesia, Sri Lanka, and India (Line 3 in Figure 1). The Maritime Silk Road has two routes: one from Quanzhou, Guangzhou, China, through Kenya to Greece (Line 4 in Figure 1). The other route is from China through Malaysia and Singapore and then to the South Pacific region (Line 5 in Figure 1).

Construction Projects for the New Silk Road: The New Silk Road consists of various infrastructure projects to be implemented under the name "New Silk Road." There are six areas of infrastructure construction, including road construction, maritime networks, airline networks, oil and gas pipeline construction, electric transmission systems, and internet line construction. Representative examples of these six types of construction products include the following:

The Land Silk Road requires the construction of highways and railroads such as the China-Pakistan Railway from Karachi to lslamabad, the Tajikistan-Uzbekistan Highway by China Communication Construction Company, and the Ethiopian Railway from Addis Ababa to Mieso by China Railway Engineering Corporation.

The maritime route requires new seaport networks operated by China, including the Port of Colombo in Sri Lanka and the Port of Vinalines in Greece and new container-shipping schedules between Shantou and Manila North Port and between Shanghai and Manila North Port.

The opening of new flight routes such as Beijing-Johannesburg, Beijing-Addis Ababa, Beijing-Minsk-Budapest, Guangzhou-Sabah (Malaysia), Guangzhou-Krabi (Thailand), and Guangzhou- Nairobi are examples of the New Silk Road airline network.

The construction of oil and gas pipelines include China-Russia, China- Kazakhstan, and China-Myanmar oil transport pipelines and China-Russia and China-Myanmar gas pipelines. China is now constructing electric transmission lines with Laos, Myanmar, and Vietnam to support Hong Kong, Macau, and the southern region of China. In addition, China's State Grid Corporation is building electric transmission lines with Russia, Mongolia, Kazakhstan, and Pakistan. For the information network, China Unicom is planning to construct infrastructure systems for internet connections in Myanmar, Vietnam, and Laos as well as undersea cable lines connecting Asia, Africa, and Europe.

Financial Support System: To support investment and financing for the New Silk Road, the Chinese government has established three financial organizations: The Asia Infrastructure Investment Bank (AIIB), which already has 57 countries as founding 
members; the New Development Bank (NDB), referred to as the BRICS Development Bank, which is led by Brazil, Russia, India, and South Africa; and the Silk Road Fund, which is jointly funded by the Chinese foreign exchange reserve, China Investment Corporation, China Development Bank, and Export-Import Bank of China.

Principles of the New Silk Road: First, the New Silk Road pursues a win-win situation for member countries. Second, the New Silk Road embodies inclusiveness. That is, the policy is open to any country wishing to be a member. Finally, the New Silk Road operates based on the market-oriented rule and derives government support if needed.

\section{The Network Structure without China and Westem European Countries}

To analyze the effects of the New Silk Road policy, this paper defines the inter-country trade value as a proxy for inter-country economic relationships. This is justified by the fact that the main purpose of the New Silk Road policy is to enhance the volume of trade and logistics. Trade data are collected from 74 countries for the year 2013. All those countries along the path of the New Silk Road are included.

For the 2013 trade value, each link is weighted by its trade value. The top $20 \%$ of all links explain more than $88 \%$ of the total trade dataset, and therefore those links belonging to this $20 \%$ are evaluated. That is, the minimum trade value for the top $20 \%$ is $\$ 896$ million, and any link less than that value is excluded from the dataset. The remaining dataset is then converted into 1, 2, 3, 4 based on the trade value.

To examine the effects of the New Silk Road policy, networks are divided into two groups: a whole network including all countries and a network without China and Western European countries such as Germany. This is done to identify country-specific effects or relationships and gain deeper insights into each network under different conditions.

Using the SNA method, which is widely used in social sciences (Scott, 2000; Wasserman \& Faust, 1994), the paper employs three main SNA indicators: degree centrality, betweenness centrality, and community modularity.

Among these standard centrality measures, proposed in Freeman (1979), degree centrality and betweenness centrality explain the influence of a country (node) or its relative role in a complex network (Borgatti \& Li, 2009; Ducruet \& Lugo, 2013; Lee \& Hyun, 2014; Lee \& Wang, 2012; Kim et al., 2011; Schiavo et al., 2010).

Degree centrality is considered the most widely used SNA measure (Scott, 2000) and calculated from weighted links directly connected to a particular node. Therefore, each node has a value such that the larger the directly linked node, the higher the degree 
centrality is. Here a node with high degree centrality maintains multiple links with other nodes in the network. Therefore, the centrality index relies on the strength of relationships and can represent countries playing a role as hubs in international trade (Borgatti \& Li, 2009).

Betweenness centrality is also a popular measure and defined as the probability that node $\mathrm{C}$ is located in the shortest path between nodes $\mathrm{A}$ and $\mathrm{B}$. The higher the betweenness centrality of a node, the more likely it is to influence other nodes in the network (Friedkin, 1991; Newman, 2003). Therefore, a country with high betweenness centrality is likely to play a role as a hub in the trade network (da Rocha, 2009). The more central the node, the larger the number of shortest paths passing through the node is (Barthélemy, 2011). 1)

For the structural position of countries in the inter-country trade network, those countries with high degree centrality have large numbers of direct relationships with their trading partners. On the other hand, countries with high betweenness centrality are more likely to act as brokers or gatekeepers connecting countries and subregions, thereby handling inter-country trade flow through the network.

\section{Table 1.}

10 most central countries excluding China and Western Europe

\begin{tabular}{c|c|c|c}
\hline & Indegree centrality & Outdegree centrality & Betweenness centrality \\
\hline 1 & Turkey & Russia & India \\
\hline 2 & Russia & India & Turkey \\
\hline 3 & India, Poland & Turkey & Russia \\
\hline 4 & Ukraine & Ukraine & Saudi Arabia \\
\hline 5 & Romania & Poland, Czech Rep. & Ukraine \\
\hline 6 & Czech Rep., Hungary & - & Azerbajian \\
\hline 7 & - & Hungary & Kazakhstan \\
\hline 8 & Slovakia & Slovakia, Saudi Arabia & Poland \\
\hline 9 & Saudi Arabia & - & Czech Rep. \\
\hline 10 & Israel & Kazakhstan & Ukraine \\
\hline
\end{tabular}

Notes: Exports are represented by outdegree centrality, whereas imports, by indegree centrality.

1) The betweenness centrality of node $i$ is calculated by $\frac{\sum_{j<k} g_{j k(n i)} / g_{j k}}{(g-1)(g-2)}$. Here $(g-1)(g-2) / 2$ is the number of node pairs not passing node $i$, and $\sum_{j<k} g_{j k(n i)} / g_{j k}$ is the probability of node $i$ being located in the shortest path between nodes $j$ and $k$ (Wasserman \& Faust, 1994). 
In this paper, those focal countries in the international trade network without China and Western European countries include India, Russia, and Turkey. Kazakhstan and Saudi Arabia belong to the top 10 high-centrality countries (Table $1 \&$ Figures 2 and 3). This result has two important implications for the New Silk Road policy.

First, the successful launch of the New Silk Road depends on how effectively the Chinese government can incorporate India, Russia, and Turkey into the new trade route system. It is crucial that the Chinese government maintain a harmonious relationship with India, which is considered a rival country.

Second, all countries in the Middle East, South Asia, and Central Asia except for Saudi Arabia and Kazakhstan reveal no meaningful status in the whole New Silk Road system. Therefore, the success of the New Silk Road policy depends on how the Chinese government brings about the maximum potential of these countries, which are largely underdeveloped and isolated.

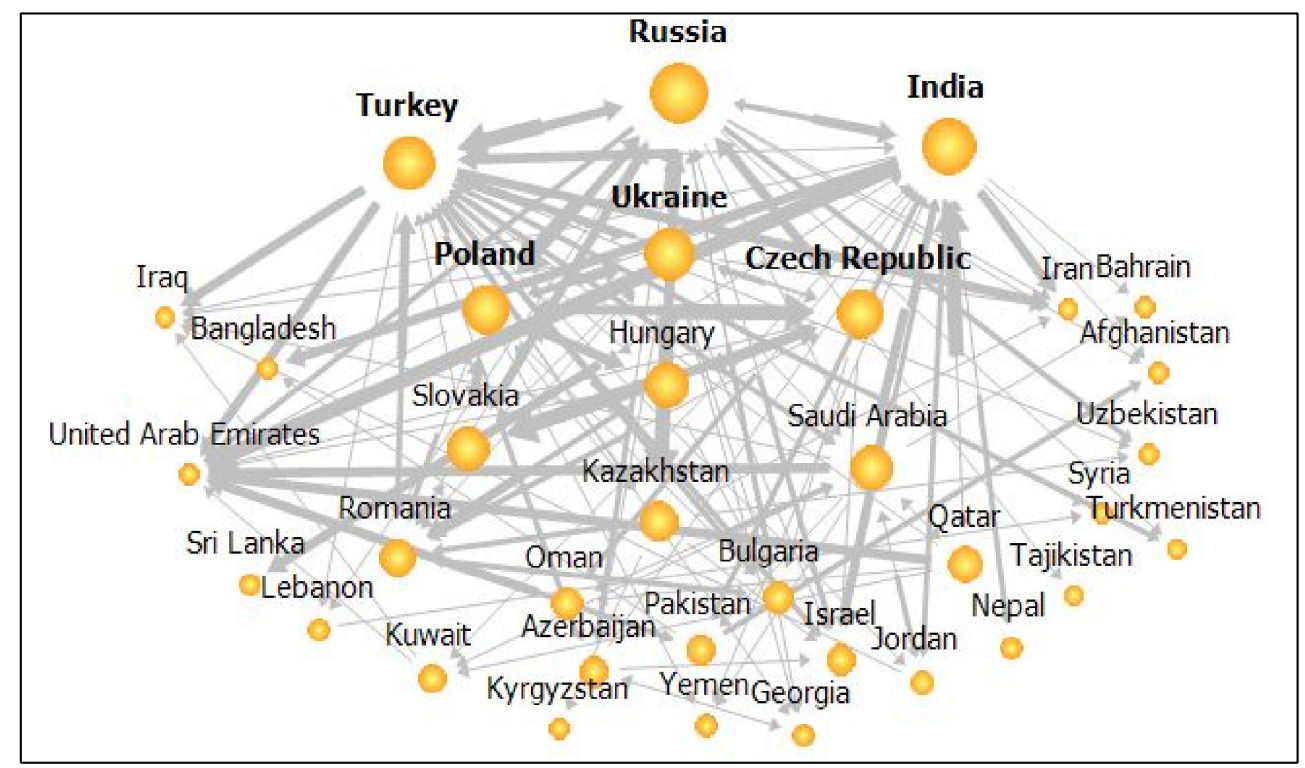

Figure 2.

The outdegree centrality of countries excluding China and Western Europe 


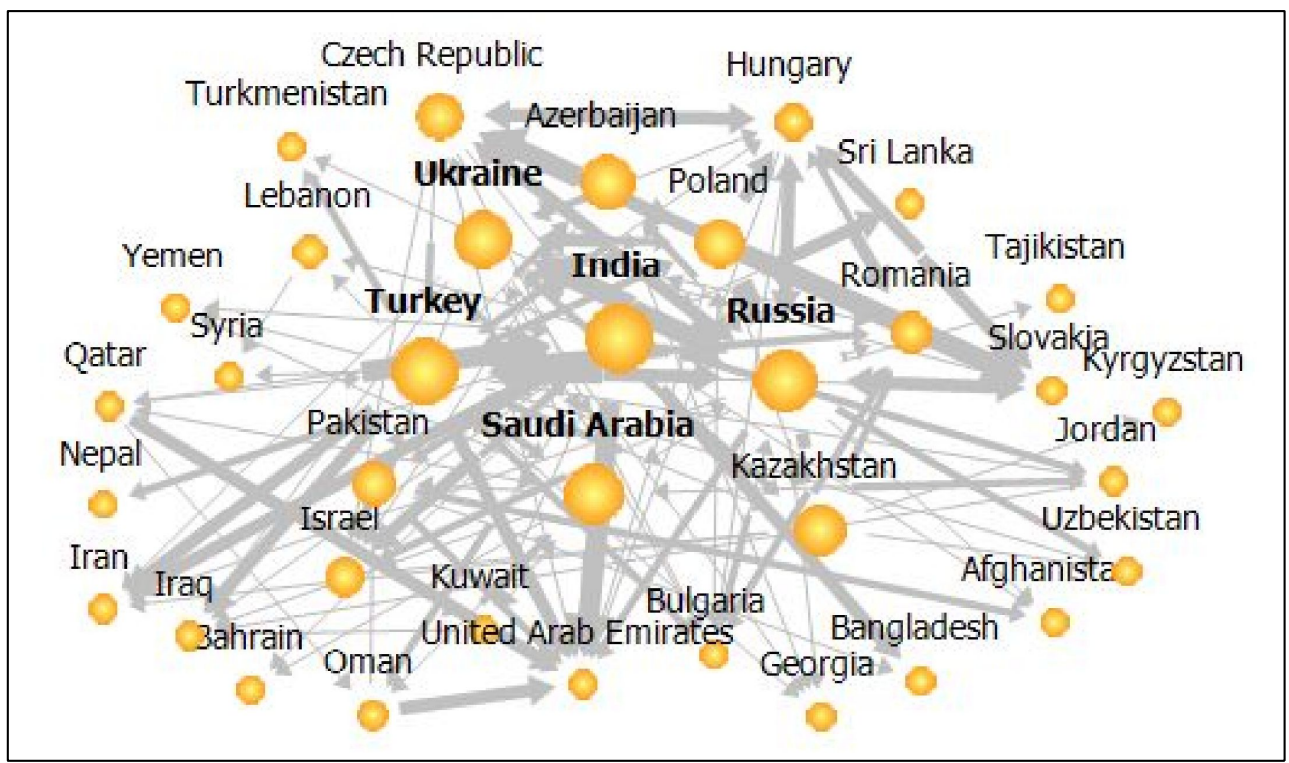

Figure 3.

The betweenness centrality of countries excluding China and Western Europe

In terms of the community structure, which is evaluated to identify multiple networks of inter-country trade relationships, the concept of community is crucial for realizing structural and functional properties of the network, which reflects the collective solidarity of members at the micro level (Barigozzi et al., 2011; Bulmer, 1985). Based on community modularity, ${ }^{2}$ ) which is assessed to capture the group structure of the network, each country in the network can be classified into a specific group in which in-group links exceed out-of-group ones. In general, belonging to the same group may be classified in accordance to a country's structural position in the New Silk Road's intertwined set of economic relationships between diverse countries. Otherwise, countries belonging to different groups are weakly connected to those outside their groups.

2) Modularity is often used in optimization methods to find the community structure of a network and is designed to measure the density of links within a community (also referred to as a group of clusters) in comparison to that of links between communities (Zhong et al., 2014). 


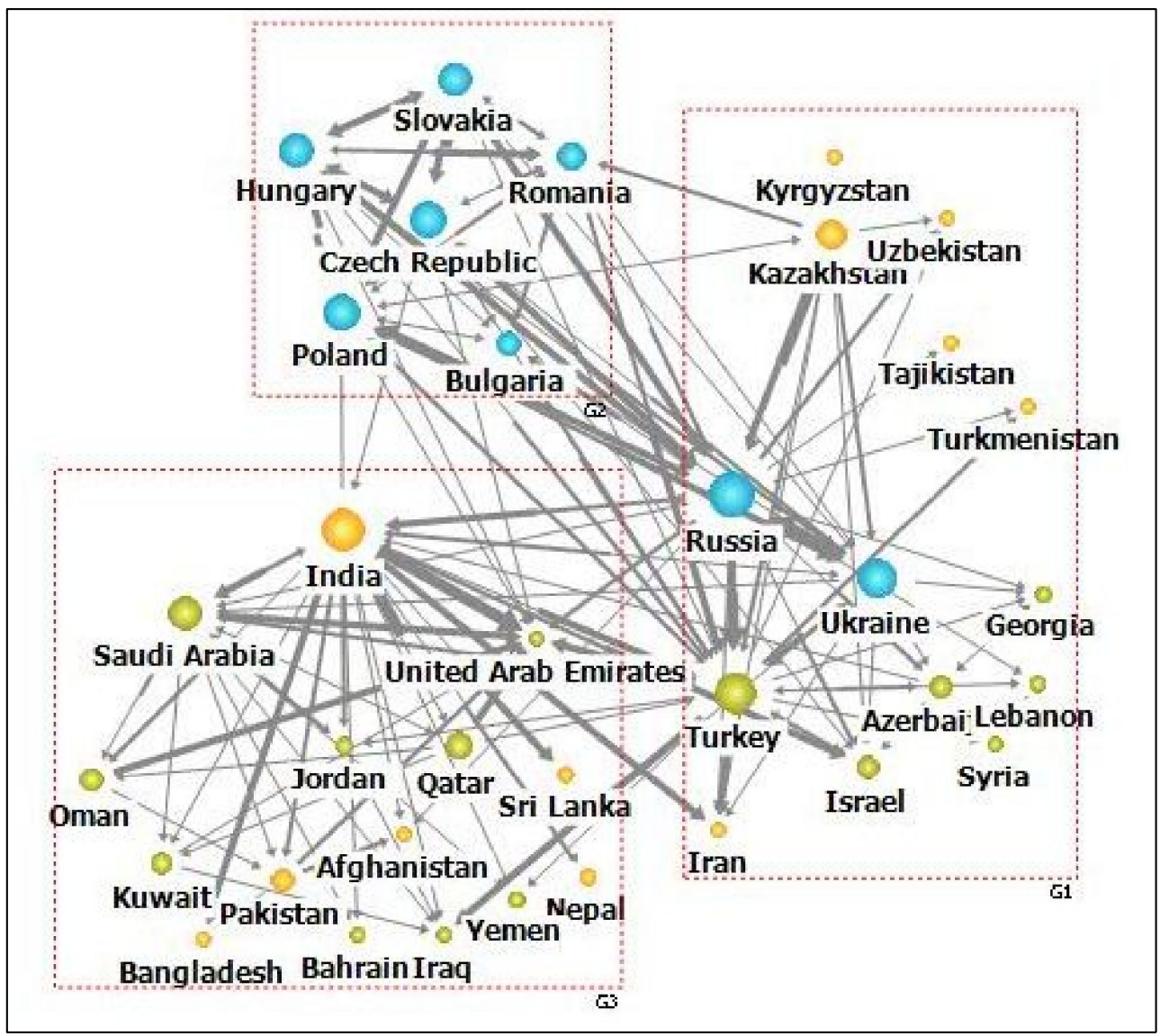

Figure 4.

The community modularity of the network excluding China and Western Europe

Note: Different node colors indicate different geographic regions

As shown in Figure 4, the network without China and Western Europe can be divided into three groups: Russia and Turkey belonging to one group, the Czech Republic being a focal country in the Eastern European group, and India as a hub in the Middle Eastern group. 


\section{The Network Structure with China}

If China and Western European countries are included in the network, then a network in which China and Germany play hub roles appears, indicating that China and Germany are two principle axes in the New Silk Road system, with Russia, India, Japan, and Korea being subsidiary countries (Figure 5).

In this sense, the construction of the New Silk Road may be interpreted as a direct connection between China and Germany transformed into indirect connections between China, subsidiary countries, and Germany. Noteworthy is that, except for Germany, most of the Western European countries do not actively converged to the whole system (Figures 5 and 6). For example, France ranks only 10th in outdegree centrality (Table 2).

More importantly, all countries in Central Asia, which may be important hubs in the New Silk Road, reveal low centrality, indicating their weak network status. This implies the serious challenges the Chinese government may face in building the New Silk Road.

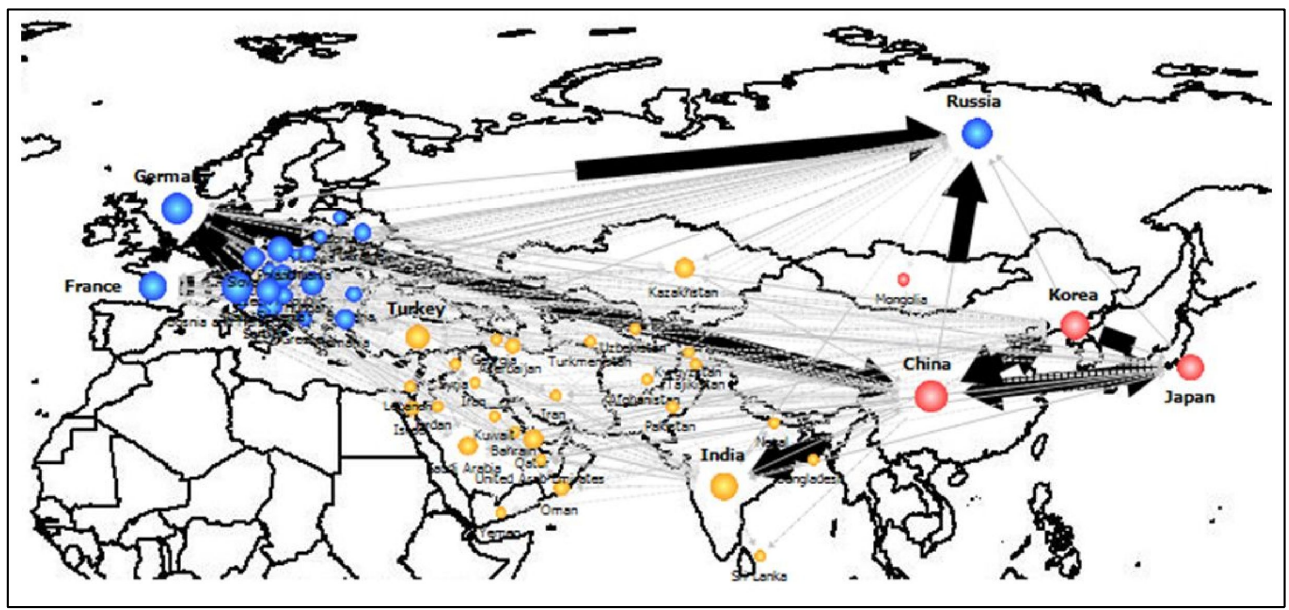

Figure 5.

The outdegree centrality of countries in the whole network

Note: The larger the circle, the higher the degree centrality is in the network. The thicker the line, the stronger the network relationship is between countries. 
Table 2.

Top 10 countries by degree and betweenness centrality

\begin{tabular}{c|c|c|c}
\hline Indegree centrality & $\begin{array}{c}\text { Outdegree } \\
\text { centrality }\end{array}$ & $\begin{array}{c}\text { Betweenness } \\
\text { centrality }\end{array}$ \\
\hline 1 & Germany & China & China \\
\hline 2 & China & Germany & Germany \\
\hline 3 & Russia & Russia & Turkey \\
\hline 4 & Turkey & India & India \\
\hline 5 & UAE, Poland & Turkey & Russia \\
\hline 6 & - & Poland & Pakistan \\
\hline 7 & India & Czech Rep. & Saudi Arabia \\
\hline 8 & Hungary & Hungary & Romania \\
\hline 9 & Ukraine, Czech Rep. & Slovakia & Ukraine \\
\hline 10 & - & France & Poland \\
\hline
\end{tabular}

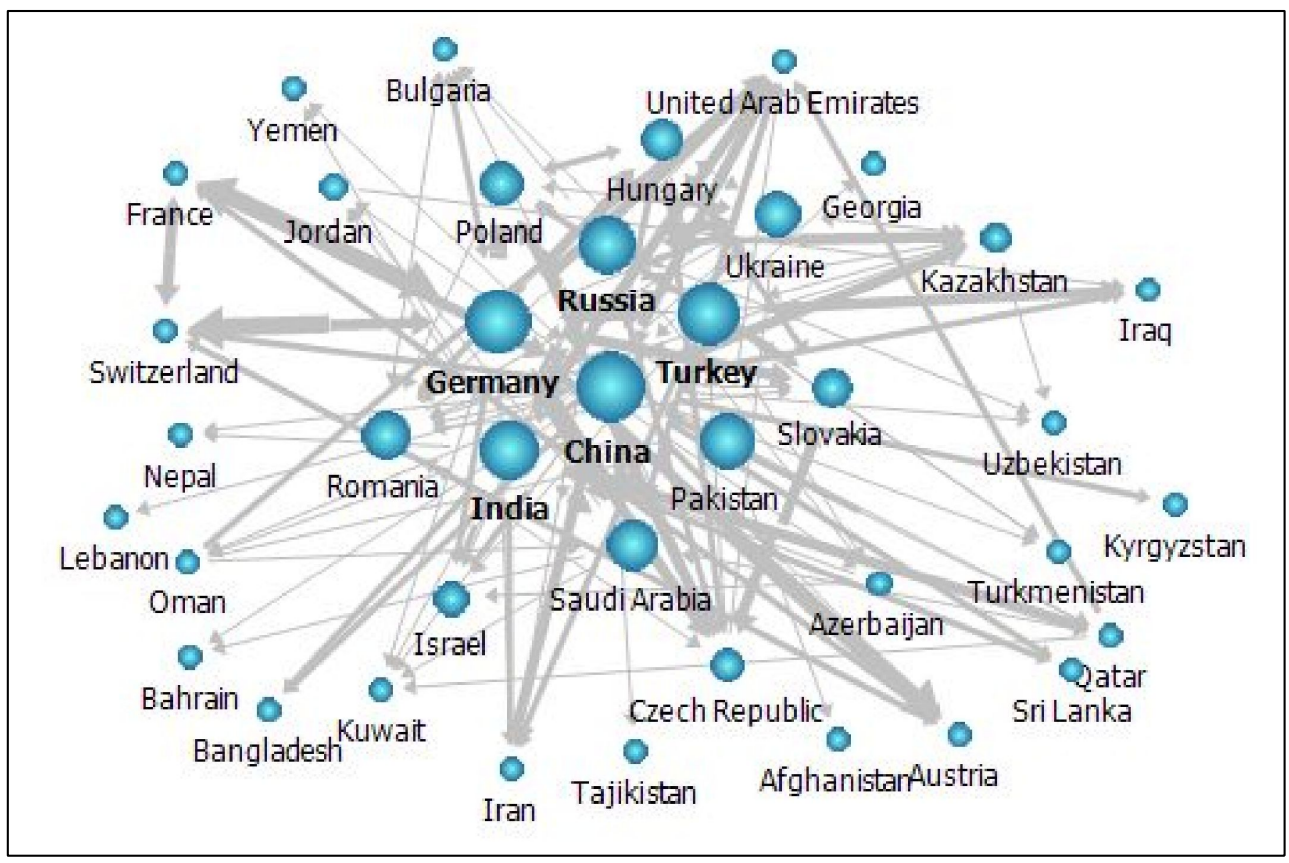

Figure 6.

Betweenness centrality with China and Europe 
The most important phenomenon is that China dominates the whole network. That is, the network structure and the status of each country do not change after excluding Germany (Figure 7).

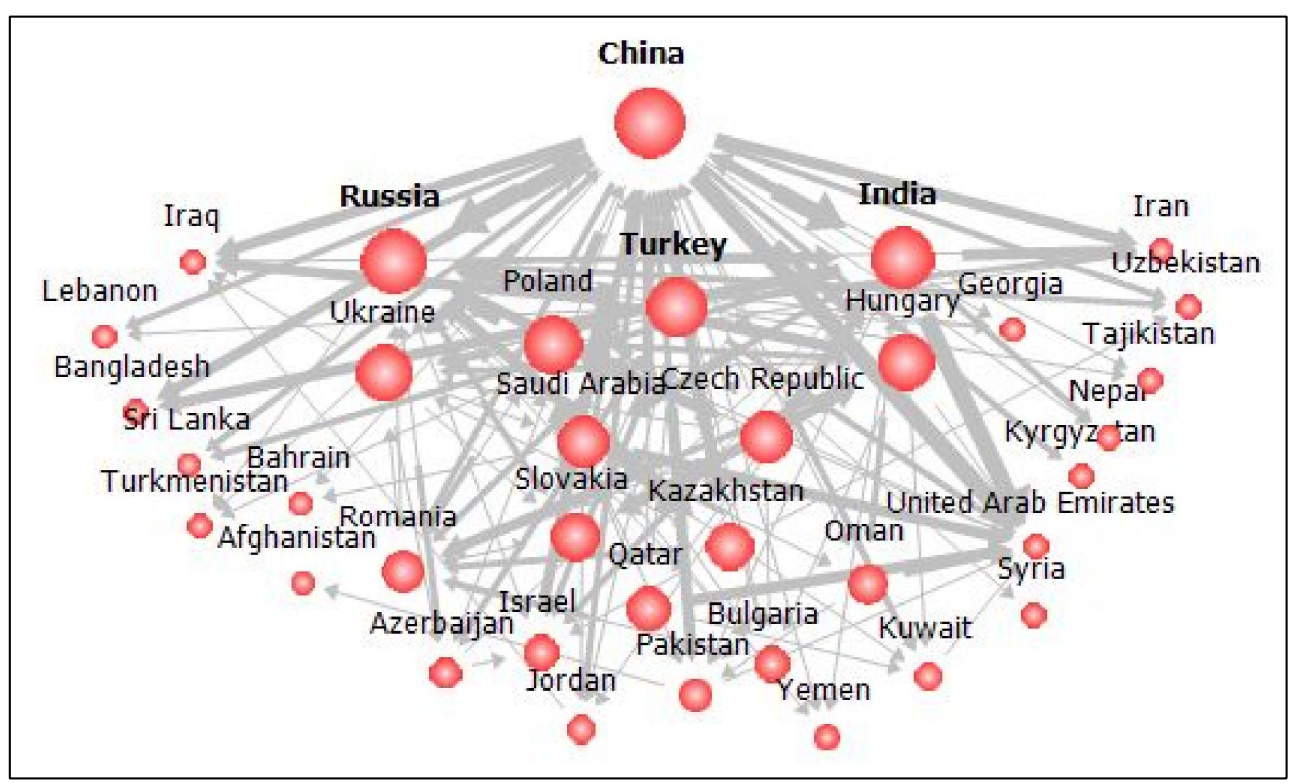

Figure 7.

Outdegree centrality only with China

Table 3.

Network properties

\begin{tabular}{c|c|c|c|c}
\hline & Number of links & Density & $\begin{array}{c}\text { Clustering } \\
\text { coefficient }\end{array}$ & Mean distance \\
\hline $\begin{array}{c}\text { Without China } \\
\text { and Germany }\end{array}$ & 181 & 0.034 & 0.760 & 2.016 \\
\hline With China & 194 & 0.036 & 0.822 & 1.819 \\
\hline $\begin{array}{c}\text { With China and } \\
\text { Germany }\end{array}$ & 211 & 0.039 & 0.820 & 1.826 \\
\hline
\end{tabular}

Note: The clustering coefficient is the percentage of links actually connected to a node, and it is calculated by the ratio of the number of observed connections to that of maximum possible connections between its neighboring nodes. The clustering coefficient for the whole network is the average clustering coefficient for all nodes (Watts \& Strogatz, 1998). 
Table 3 compares the properties of the trade network by considering diverse groups of countries, including their density, clustering coefficients, and mean distance. Network density refers to the ratio of existing links to the total number of all possible links. In a trade network, density describes how closely countries connected to others. Therefore, an increase in network density increases the integration of member countries in the trading block and the flow of goods, services, and capital across the network.

The clustering coefficient identifies the extent to which neighboring nodes of a certain node are linked is a key property of any network (Li \& Cai, 2007). In terms of the inter-country trade network, the clustering coefficient is defined as the probability of two countries being directly connected to a third country while being directly connected to each other. A clustering coefficient close to 1 implies a strong economic relationship within the network. According to the clustering coefficient analysis, there are no differences in indices between the network only with China and that with China and Europe. Even the mean distance (where the smaller the number, the more efficient the network) is shorter in the network only with China than in that with China and Europe.

\section{Policy Implications and Concluding Remarks}

Using the SNA method, this paper examines the features of China's New Silk Road initiative. The results have several important implications:

First, among subsidiary countries, India, Turkey, and Russia have the highest degree centrality, indicating that the success of the New Silk Road policy depends mainly on the ability of the Chinese government to incorporate these countries. In the same sense, India, generally considered a rival to China, is a hub but may lose its focal status in the network if the New Silk Road is organized to increase interconnections between China and Central Asian countries.

Second, for European countries, only Germany is successfully incorporated into the New Silk Road network. That is, most of the Western European countries have no considerable influence on the network. On the other hand, Eastern European countries are more likely to benefit from the New Silk Road network.

Third, Central Asian countries such as Kazakhstan and Uzbekistan have no hub status in the network. This indicates that the region poses a serious challenge to China even if the Chinese government makes efforts to enhance these countries' network status.

Finally (and most importantly), China dominates the New Silk Road. This focal status of China is supported by the fact that there is no difference in the clustering coefficient 
between the network only with China and that with China and Europe. This implies that the Chinese government is likely to face some difficulty in trying to absorb into the network other countries that are less likely benefit from the policy.

The fact that the New Silk Road policy focuses mainly on Central Asia presents Korean policymakers with a serious challenge. For Korea to be included in the network, the most plausible way may be to enlarge the route through Northeast China, North Korea, and the Pacific Ocean. 


\section{References}

Barigozzi, M., Fagiolo, G. and Mangioni, G. (2011) "Community Structure in the Multi-network of International Trade," Communications in Computer and Information Science 116, 163-175.

Barthélemy, M. (2011) “Spatial Networks,” Physics Reports, 499, 1-101.

Borgatti, S. P., Li, X. (2009) "On Social Network Analysis in a Supply Chain Context," Journal of Supply Chain Management, 45(2), 5-22.

Bulmer, M. (1985) “The Rejuvenation of Community Studies? Neighbours, Networks, and Policy," Sociological Review 33(3), 430-448.

da Rocha, L. E. C. (2009) "Structural Evolution of Brazilian Airport Network," Journal of Statistical Mechanics: Theory and Experiment, 4, P04020.

Ducruet, C., Lugo, I. (2013) Structure and Dynamics of Transportation Networks: Models, Methods and Applications, in Rodrigue, J-P., Notteboom, T. E. \& Shaw, J. (Eds.), The SAGE Handbook of Transport Studies, London: SAGE Publications, 347-364.

Freeman, L. C. (1979) "Centrality in Social Networks: Conceptual Clarification," Social Network, 1(3), 215-239.

Friedkin, N. E. (1991) “Theoretical Foundations for Centrality Measures," The American Journal of Sociology, 96(6), 1478-1504.

Kim, Y., Choi, T. Y., Yan, T. and Dooley, K. (2011) "Structural Investigation of Supply networks: a Social Network Analysis Approach," Journal of Operational Management, 29, 194-211.

Lee, J. Y., Hyun, K. (2014) "Airline Network in East Asia," Journal of International Logistics and Trade, 12(3), 21-37.

Lee, J. Y., Wang, S. (2012) "Inter-Provincial Railroad Network in China," Journal of International Logistics and Trade, 10(2), 61-75. 
Li, W., Cai, X. (2007) "Empirical Analysis of a Scale Free Railway Network in China," Physica A, 382, 693-703.

Newman, M. E. J. (2003) "Ego-centered Networks and the Ripple Effect," Social Networks 25, 83-95.

Schiavo, S., Reyes, J. and Fagiolo, G. (2010) "International Trade and Financial Integration: a Weighted Network Analysis,” Quantitative Finance, 10(4), 389-399.

Scott, J. (2000) Social Network Analysis: a Handbook, London: Sage Publications.

Wasserman, S., Faust, K. (1994) Social Network Analysis: Methods and Applications, NewYork: Cambridge University Press.

Watts, D. J., Strogatz, S. H. (1998) "Collective Dynamics of 'Small-World' Networks," Nature, 393, 409-410.

Zhong, W., An, H., Gao, X. and Sun, X. (2014) "The Evolution of Communities in the International Oil Network," Physica A, 413, 42-52. 